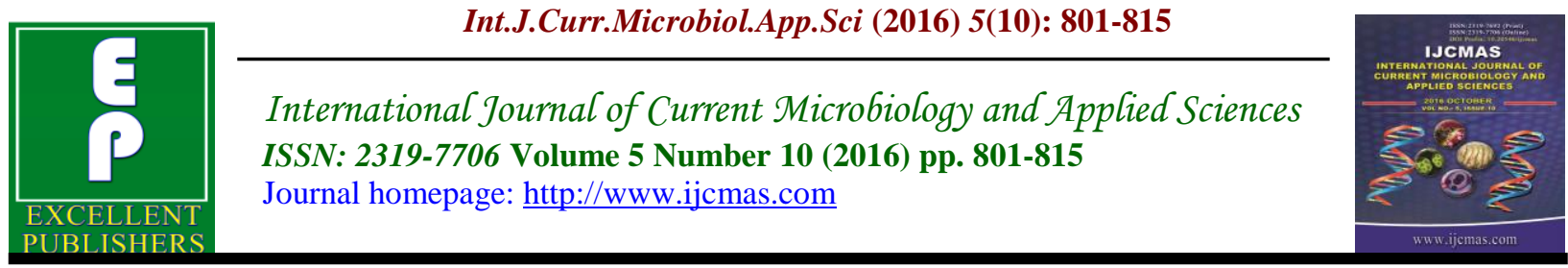

Original Research Article

http://dx.doi.org/10.20546/ijcmas.2016.509.091

\title{
Comparative Study between Febuxostat and Allupurinol based on Safety and Urate-Lowering Efficacy in Gout Patients of Indian Population
}

\author{
Shikhar Tyagi*, Shalini Rawat and Sarika Saxena \\ Amity Institute of Biotechnology, Amity University, Sector-125, Noida, UP, India \\ *Corresponding author
}

A B S T R A C T

Keywords

Febuxostat, Allopurinol, Gout,

Uric acid, Uricostatic drugs, Hyperuricemia, Xanthine Oxidase.

\section{Article Info}

Accepted:

20 September 2016

Available Online:

10 October 2016
Gout is an ataxia evident as a continuum of medical and pathologic portions developed as an establishment when the body has surplus amounts of uric acid, appearing bit by bit by hyperuricemia. This is often depicted by serum urate levels greater than either 6.8 or $7.0 \mathrm{mg} / \mathrm{dl}$. Gout can additionally show up as perpetual joint irritation of 1 or more joints. Gout is typical provocative joint exacerbation connected with essential co-morbidities including hypertension, renal impedance, cardiovascular ailment, weight and Type 2 diabetes. Age, sex, genetic and racerelated risks, diet (especially purine rich substances) and a number of pharmaceuticals (thiazide, loop diuretics, ACE inhibitors, and beta blockers) have been found as hazardous variables for improvement of Gout. Gout occurs more in men than ladies and rarely happens in premenopausal Women. Uricostatic drugs (Xanthine oxidase inhibitors) are extensively and most commonly used for the treatment of chronic gout. This study is planned to look at the adequacy of two uric acid chopping down medications (Febuxostat and Allopurinol) for giving symptomatic pain relief and overhauling the utilitarian condition of the patients. Administration of Febuxostat and Allopurinol in Gout patients has emerged to be clinically effective in lowering down the uric acid levels as well as providing symbolic suitable deprivation of pain. In the perspective of undeniable statistical information, we consider that febuxostat should serve as primary choice of drug if early essential and considerable symptomatic improvements are taken into consideration.

\section{Introduction}

Gout is a form of arthritis with a documented history spanning several thousands of years. Observed by the ancient Egyptian medical practitioner Imhotep as early as 2640BCE, it was also described several centuries later by the Greek physician Hippocrates (400BCE), the father of modern medicine, who referred to it as podagra, or "the unwalkable disease". Gout represents the most frequent inflammatory joint disease in the general population 1 , and it largely contributes to healthcare burden (Smith et al., 2014). Monosodium urate deposition due to longstanding hyperuricemia leading to urate crystal formation in tissues represents the 
pathophysiological mechanism of gout (Doherty et al., 2012). Recent evidence suggests that the mean serum urate (sUA) levels in the general population are increasing worldwide, due to a number of factors such as the "epidemic" of overweight and obesity in developed countries, as well as the shifts in diet with overconsumption of foods rich in purines, alcohol, fructosesweetened soft drinks (Desideri et al., 2014; Choi et al., 2005, 2008), in addition to the use of diuretic drugs to treat comorbid conditions. Of note, patients with gout often present comorbid conditions in addition to obesity, such as cardiovascular diseases, arterial hypertension, diabetes mellitus, and chronic kidney disease (CKD) (Borghi et al., 2015). There is evidence suggesting that increased sUA may be a risk factor also of these conditions (Richette et al., 2015; Agabiti-Rosei et al., 2013; Ruilope et al., 2013). The management of hyperuricemia thus represents the key strategy in the treatment of gout and, potentially, of associated diseases. A number of guidelines are available to improve gout management and reduce hyperuricemia (Zhang et al., 2006). In particular, sUA should be generally lowered below the target of 6 $\mathrm{mg} / \mathrm{dL}$, and even further below $5 \mathrm{mg} / \mathrm{dL}$ in patients with severe gout (Khanna et al., 2012). To achieve this goal, urate lowering therapies (ULTs) should be considered and discussed with patients prescribed as soon as diagnosis of gout is established. Currentlyused ULTs include xanthine-oxidase inhibitors such as allopurinol, febuxostat, and topiroxostat (labelled only in Japan), as well as uricosuric agents, such as benzbromarone and probenecid. However, evidence directly comparing these two classes of drugs remains scant.

Incidence of gout in India is not very clear. The prevalence is $0.12 \%$ as per International League of Nations against Rheumatism,
Community Oriented Program for Control of Rheumatic Diseases (ILAR COPCORD) study in Bhigwan village of India. A study from Vellore revealed that $15.8 \%$ of the affected patients are less than 30 years of age; urban Indian population is involved more than the rural population and due to increased prevalence of metabolic syndrome in younger population, the first attack of gout occurs a decade earlier to them. Another Indian study showed that high uric acid level is associated with laboratory and anthropometric parameters of metabolic syndrome (Misra et al., 2008).

There are four stages of gout, first is Asymptomatic Hyperuricemia. Elevated levels of urate are present within the body, but the individual does not display symptoms clinically. Stage 2 , an acute gout attack or flare, comprises of the buildup and small deposits of monosodium urate crystals in and around specific joint spaces. Characteristically, the patient may suffer pain, redness, swelling, and warmth, which may last for lengths of time ranging from days to weeks. Stage 3, Intercritical Gout occurs in a patient who had prior gout flares, which have successfully subsided and who has no current expression of gout symptoms. A patient may report normal joint function, though hyperuricemia continues to occur with an increasingly greater possibility for damage in tissues due to continued deposition of urate crystals. The final stage of progression, Chronic Gout, is typified by a resulting destructive and disabling inflammatory process causing ongoing pain and aching of the joint(s). Chronic tophaceous arthritis is a product of the continuous deposition of urate crystals around and within the joint space. In multiple cases, deformities and destruction of the bone and joints involved have occurred, causing a reduction in quality of life due to the damage and pain. 
Diagnosis of gout includes joint aspiration and synovial fluid analysis, serum uric acid measurement, 24 hour urinary uric acid evaluation, blood studies (including white blood cells, triglyceride, high density lipoprotein, glucose and renal and liver function tests).

The gold standard for the diagnosis of acute gout is the demonstration of strongly negative birefringent needle and rod-shaped crystals of MSU in the synovial fluid under compensated polarizing light microscopy. American College of Rheumatology Criteria for the Classification of Acute Arthritis for Primary Gout (Wallace et al., 1977) is used to confirm the diagnosis of gout.

The main therapeutic agents for the treatment of acute attacks are colchicine, non-steroidal anti-inflammatory drugs (NSAIDs) and corticosteroids. The American College of Rheumatology guidelines recommend either allopurinol or febuxostat as first line therapy; however, third-party payers often stipulate allopurinol use first due to the substantial cost difference. Colchicine is the ideal drug in patients where the diagnosis of gout is not confirmed. It acts by inhibiting the action of neutrophils (Nuki, 2008). Chronic gout is treated with urate lowering drugs. About $1 / 3$ rd of patients with an attack of gout have a second attack within one year. So it is imperative to have prophylactic use of urate lowering drugs. Uricostatic drugs (xanthine oxidase inhibitor) such as Allopurinol and febuxostat.

Allopurinol is non selective xanthine oxidase (XO) inhibitor that decreases acute gout attack incidence by decreasing the amount of serum uric acid through the inhibition of xanthine oxidase enzyme, which is involved in uric acid synthesis. It acts on purine catabolism, without disrupting the biosynthesis of purines. It is a commonly prescribed urocostatic pro drug that is converted in the liver to the active metabolite oxypurinol.

Febuxostat, is a non-purine analogue $\mathrm{XO}$ inhibitor. The FDA approved Febuxostat in February 2009. It inhibits both the reduced and oxidized forms of the enzyme in contrast to allopurinol. Febuxostat is a nonpurine analogue, and thus does not block the other metabolites of purine and have no effect on pyrimidine metabolism. All these help to alleviate allopurinol toxicities. Another advantage is its effectiveness in mild to moderate renal failure. Major side effects include rash, elevated liver enzymes, diarrhoea and non-specific arthralgia's. There is lesser drug interaction with azathioprine, 6-mercaptopurine and theophylline.

The present study aimed to compare the efficacy of two urate lowering drugs (Allopurinol and Febuxostat) for providing symptomatic pain relief and improving the functional state of the patients having gout. Moreover, there is very less data available on the comparison of two drugs using VAS scale, further divided into three parts namely subject's assessment of pain (SAP), subject's assessment of disease activity (SAD) and physician's assessment of disease activity (PAD). So we planned the study to get adequate data on Indian population in terms of efficacy, safety, duration of action and reduction in serum uric acid level in gout patients with the use of these two drugs.

\section{Materials and Methods}

The study was conducted at Department Of Orthopedics, Nova Specialty Hospitals, Kailash Colony, New Delhi during the period from January 2015 to June 2015. A 
retrospective, single blind, randomized, comparative model was designed for the study. Both male and female patients with 30-75 years of age, serum uric acid $\geq 8.0$ $\mathrm{mg} / \mathrm{dl}$ (hyperuricemia) who are not under treatment with any uric-acid lowering drugs, who met the American college of rheumatology criteria for diagnosis of gout, presence of Monosodium urate monohydrate microcrystals in joint fluid, a self-reported history of $\geq 2$ gout flares in the year prior to initial screening visits, patients who are allowed to be on urate lowering therapy and who agreed to sign the informed consent were included in the study. Patients with secondary hyperuricemia, xanthinuria, previous history of hypersensitivity to NSAIDs, colchicine, allopurinol and febuxostat, who had gout attack in last two weeks, patients with aspirin-induced asthma, peptic ulcer, serious hematological disorder, uncontrolled diabetes, who require dialysis, and who are being treated with any systemic immunosuppressant were excluded from the study.

A retrospective, single blind, randomized, comparative model was designed for the study. A total number of 65 patients were assessed for the study. Each patient was followed up for 1 year. The retrospective data was taken at the baseline, at the $4^{\text {th }}$ month, then at $8^{\text {th }}$ month and then at final follow-up. The study was done during the period from Feb 2015 to June 2015.The patient was asked about the frequency of the gout flare.

The patient was asked to fill the subject's assessment of pain (SAP) visual analogue scale and a subject's assessment of disease activity (SAD) visual analogue scale (VAS) at their follow up. A physician performed a complete physical examination (swelling, tenderness, and redness, no. of tophi, frequency of gout flares) on each patient and completed a subject's assessment of disease activity (PAD) visual analogue scale The primary outcome measures in this study were flare characteristics (tender joints, swollen joints, patient global assessment). Serum uric acid level was also analyzed at baseline and at each visit.

\section{Assessment Criteria}

A total of score obtained after scoring by the patients and physician was calculated by adding individual scores of visual analogue scale (SAP, SAD, PAD) at each visit and the total score generated was considered as the final value which was then assessed according to the statistical analyses.

\section{Statistical analysis}

The software used for the statistical analysis was SPSS (statistical package for social sciences) version 16.0 and Epi-info version 3.0. The values were represented in Number (n), Percentage (\%) and Mean (v).The statistical tests used were Unpaired or independent samples t-test for comparison of mean value of 2 groups. The p-value was taken significant when less than 0.05 $(p<0.05)$ and Confidence interval of $95 \%$ was taken.

\section{Results and Discussion}

A total of 65 subjects were assessed from February 2015 to March 2015. Eleven subjects were excluded as they did not meet inclusion criteria or fell in the exclusion criteria. One subject did not give consent for enrollment in the study and three patients did not come back for their follow up visits.

The remaining 50 subjects completed the study with 25 in Allopurinol group and 25 in Febuxostat group. None of the subjects enrolled suffered from serious adverse event. All the 50 subjects completed the efficacy analysis 


\section{Efficacy End Points}

Primary END-POINT: SAP (subjects assessment of pain) after 20 meters walk

SAP (subject's assessment of pain) was taken at baseline and after every 4 months interval for 12 months. No statistical significant difference was observed at the baseline score as well as at the end of 4 months.

But there was statistical significant difference when inter group comparison was done between the two groups at the end of 8 months and 12 months.

\section{SAD (subjects assessment of disease} activity)

SAD (subject's assessment of disease activity) was taken at baseline and after every 4 months interval for 12 months. No statistical significant difference was observed at the baseline score. But there was statistical significant difference when inter group comparison was done between the two groups at the end of 4 months till the end of 12 months.

\section{PAD (physician's assessment of disease} activity)

PAD (physician's assessment of disease activity) was taken at baseline and after every 4 months interval for 12 months. No statistical significant difference was observed at the baseline score as well as after the end of 4 months.

But there was statistical significant difference when inter group comparison was done between the two groups at the end of 8 months till the end of 12 months.

\section{Secondary end points}

\section{Serum uric acid level}

Serum uric acid level was taken at baseline and after every 4 months interval for 12 months. No statistical significant difference was observed at the baseline score as well as after the end of 4 months. But there was statistical significant difference when inter group comparison was done between the two groups at the end of 8 months till the end of 12 months.

\section{Number of Tophi}

Number of tophi was taken at baseline and after every 4 months interval for 12 months. No statistical significant difference was observed at the baseline score. But there was statistical significant difference when inter group comparison was done between the two groups at the end of 4 months and at the end of 12 months.

\section{Gout Flares}

Gout flares was taken at baseline and after every 4 months interval for 12 months. No statistical significant difference was observed at the baseline score till the end of 8 months. But there was statistical significant difference when inter group comparison was done between the two groups at the end of 12 months.

\section{Safety End-Points}

No serious adverse events were reported by the subjects during the study period.

The study was designed to confirm the effects of the two most commonly used urate lowering drugs (Allopurinol \& Febuxostat) in patients of gout. 
Firstly, we wanted to assess out of two drugs which one is more efficacious and giving early onset of symptomatic pain relief. Secondly, which one is more efficacious in terms of lowering the serum uric acid level, reducing the gout flares and no. of tophi.

A study from Vellore revealed that $15.8 \%$ of the affected patients are less than 30 years of age; urban Indian population is involved more than the rural population and due to increased prevalence of metabolic syndrome in younger population, the first attack of gout occurs a decade earlier to them. Another Indian study showed that high uric acid level is associated with laboratory and anthropometric parameters of metabolic syndrome (Misra et al., 2008).

The mean age of the patients was 53.8 years, with a range of 39 to 67 years and 59.72 years, with a range of 37 to 81 years in the allopurinol and febuxostat group respectively. The incidence of gout increases rapidly between the ages of 30 and 50 years, and the prevalence then continues to increase with age.

Literature states that the prevalence of gout is generally higher in men than in women, although this is reversed after women reach menopause, whereupon women are more afflicted by gout than men (Kim et al., 2003), principally because oestrogen promotes urate wasting in the urine. In present study, most of the women enrolled in the study were postmenopausal.

It is well known that various food stuffs are associated with acute gout attacks (Choi et al., 2004). The following triggers of acute gout attacks were listed by patients at the baseline: red meat, alcoholic, beverages, tomatoes, carbonated beverages, fruit, green vegetables, white bread, sweets, nuts, porridge and fried eggs.
In present study, based on the dietary intake of the subjects, $25 \%$ were classified as red meat, $24 \%$ as alcoholic beverages, $15 \%$ as tomatoes, $13 \%$ as carbonated beverages, $8 \%$ as fruit, $4 \%$ as green vegetables, $3 \%$ as white bread and $9 \%$ as other food stuff. This clearly indicates the importance of red meat and alcoholic beverages as potential triggers for acute gout flares. Many of the patients at their follow up stated that they tried to decrease their intake of the above mentioned foodstuffs in order to avoid acute gout attacks. Increased seafood intake has long been referred to as a risk factor for gouty flares. Contrary to this, only one or two patients listed any form of seafood as a potential trigger.

The primary efficacy criterion in our study was the change in $100 \mathrm{~mm}$ VAS scale after the patient was asked to take a $20 \mathrm{~m}$ walk. Patients were asked to complete visual analogue scales at their every visit; namely subject's assessment of pain (SAP) and subject's assessment of disease activity (SAD). Physicians were asked to complete a physician's assessment of disease activity (PAD) for each patient.

All of the visual analogue scales (SAP, SAD and PAD) showed a decrease at every interval i.e. from baseline to the final follow up. In SAP, both drugs are efficacious in reducing the pain. But febuxostat gave early symptomatic pain relief and had longer duration of action in comparison to allopurinol as statistically significant difference is seen at the end of $8^{\text {th }}$ and $12^{\text {th }}$ month. In SAD, the significant difference was observed at the end of $4^{\text {th }}$ month and remained significant till the end of $12^{\text {th }}$ months. In PAD, the statistically significant difference is seen at the end of $8^{\text {th }}$ and $12^{\text {th }}$ month. 
When comparing the baseline mean subjects assessment of disease activity score to that of the baseline mean physician's assessment of disease activity score, it can be seen that patients mean score was higher than that of the physician's mean score.

This could possibly indicate that patients tend to overestimate their disease activity in periods where they do not experience gout attacks. This leads us to question whether the subject's assessment of pain was also overestimated. But unfortunately this question cannot be answered, as only the patients, not the physician, completed an assessment of pain.

Upon comparison of the follow up visit's mean assessments of disease activity, it was found that mean SAD score was high than mean PAD score at the $4^{\text {th }}$ and $8^{\text {th }}$ month interval. At the $12^{\text {th }}$ month, it was found that both the mean SAD and PAD scores were similar to each other, indicating that while each individual patient's assessment of disease activity may not have agreed with that of the physician, the general trend in mean scores shows similarity.
So, while scores shows that patients tend to overestimate the severity of their gout attacks, their scores generally remain in the same range as the physician's scores, which show that although the patient's assessment of pain and disease activity is subjective, it is still a reliable indicator of gout activity.

Visual analogue scales are frequently used to assess gout in clinical trials. As such the validity of the scale needs to be established. One research team assessed the validity of pain and patient global scales in chronic gout patients involved in the pegloticase clinical trials. They discovered that visual analogue scales correlated with results obtained from tender and swollen joint counts as well as the SF-36, a body pain subscale. The authors concluded that the visual analogue scales are valid outcome measures for the evaluation of gout patients. Another study, Taylor et al., (2012), also used VAS for measuring pain in primary joints for 10 days. Mean daily VAS pain scores did not differ significantly between study groups at any point between days 1 and 10.

Table.1 Baseline demography of study groups

\begin{tabular}{|c|c|c|c|c|c|}
\hline & \multicolumn{2}{|c|}{ MEAN } & \multicolumn{2}{|c|}{ Standard deviation } & $\mathrm{P}$ value \\
\hline & Allopurinol & Febuxostat & Allopurinol & Febuxostat & \\
\hline Age(yrs) & 53.8 & 59.72 & 9.51 & 11.94 & $\begin{array}{c}.239>.05 \text { accept null } \\
\text { hypothesis }\end{array}$ \\
\hline Sex & 1.36 & 1.4 & .49 & .50 & $\begin{array}{c}.574>.05 \text { accept null } \\
\text { hypothesis }\end{array}$ \\
\hline Weight(Kg) & 72.6 & 73.52 & 7.31 & 10.63 & $\begin{array}{c}\mathbf{. 2 > . 0 5} \text { accept null } \\
\text { hypothesis }\end{array}$ \\
\hline Height(m) & 1.62 & 1.66 & .08 & .07 & $\begin{array}{c}.72>.05 \text { accept null } \\
\text { hypothesis }\end{array}$ \\
\hline $\mathrm{BMI}\left(\mathrm{Kg} / \mathrm{m}^{2}\right)$ & 27.88 & 28.13 & 0.69 & 1.01 & $\begin{array}{c}\mathbf{9 6}>\mathbf{. 0 5} \text { accept null } \\
\text { hypothesis }\end{array}$ \\
\hline
\end{tabular}

Since in all the above cases, our $\mathrm{p}$ value is greater than 0.05 therefore we accept Ho(null hypothesis), i.e., there's no significant difference between the two study groups with respect to age, height, sex, weight and BMI. It means that the two sample groups are homogeneous. 
Table.2 Baseline assessment scores using various scales

\begin{tabular}{|c|c|c|c|c|c|}
\hline & \multicolumn{2}{|c|}{$\begin{array}{l}\text { ALLOPURINOL/ } \\
\text { FEBUXOSTAT }\end{array}$} & \multicolumn{2}{|c|}{$\begin{array}{l}\text { ALLOPURINOL/ } \\
\text { FEBUXOSTAT }\end{array}$} & \\
\hline \multirow{2}{*}{ VAS } & \multicolumn{2}{|c|}{ MEAN } & \multicolumn{2}{|c|}{ STANDARD DEVIATION } & P Value \\
\hline & & & & & \\
\hline $\begin{array}{c}\text { SAP (subjects assessment of } \\
\text { pain) }\end{array}$ & 82.80 & 82.40 & 7.37 & 7.23 & $\begin{array}{c}0.847>\mathbf{0 5} \text { accept null } \\
\text { hypothesis }\end{array}$ \\
\hline $\begin{array}{c}\text { SAD (subjects assessment of } \\
\text { disease activity) }\end{array}$ & 84.00 & 81.60 & 5.00 & 5.54 & $\begin{array}{c}0.114>.05 \text { accept null } \\
\text { hypothesis }\end{array}$ \\
\hline $\begin{array}{c}\text { PAD (physicians assessment of } \\
\text { disease activity) }\end{array}$ & 82.00 & 84.00 & 7.64 & 8.17 & $\begin{array}{c}0.376>. \mathbf{0 5} \text { accept null } \\
\text { hypothesis }\end{array}$ \\
\hline Serum Uric Acid Level & 9.13 & 9.24 & 0.45 & 0.64 & $\begin{array}{c}0.489>\mathbf{0 5} \text { accept null } \\
\text { hypothesis }\end{array}$ \\
\hline NO. of TOPHI & 4.20 & 4.40 & 0.76 & 0.50 & $\begin{array}{c}0.279>.05 \text { accept null } \\
\text { hypothesis }\end{array}$ \\
\hline Gout Flares & 4.60 & 4.80 & 0.50 & 0.41 & $\begin{array}{c}0.128>.05 \text { accept null } \\
\text { hypothesis }\end{array}$ \\
\hline
\end{tabular}

Table.3 SAP (subject's assessment of pain) from baseline to 12 months

\begin{tabular}{|c|c|c|c|c|c|c|}
\hline $\begin{array}{l}\text { SAP (subjects } \\
\text { assessment of pain) }\end{array}$ & $\begin{array}{l}\text { Drug } \\
\text { group }\end{array}$ & Mean & S.D. & $\begin{array}{l}\text { t-test } \\
\text { value }\end{array}$ & $\begin{array}{l}\text { Mean } \\
\text { Difference }\end{array}$ & $\begin{array}{l}P \text { - } \\
\text { value }\end{array}$ \\
\hline \multirow[t]{2}{*}{ Baseline } & Allopurinol & 82.80 & 7.37 & 0.194 & 0.400 & 0.847 \\
\hline & Febuxostat & 82.40 & 7.23 & & & \\
\hline \multirow[t]{2}{*}{ At 4 months } & Allopurinol & 58.80 & 7.81 & 1.510 & 2.800 & 0.138 \\
\hline & Febuxostat & 56.00 & 5.00 & & & \\
\hline \multirow[t]{2}{*}{ At 8 months } & Allopurinol & 50.40 & 14.57 & 2.140 & 9.600 & $0.038 *$ \\
\hline & Febuxostat & 40.80 & 17.06 & & & \\
\hline \multirow[t]{2}{*}{ At 12 months } & Allopurinol & 30.00 & 10.41 & 3.578 & 8.000 & $0.001 *$ \\
\hline & Febuxostat & 22.00 & 4.08 & & & \\
\hline
\end{tabular}

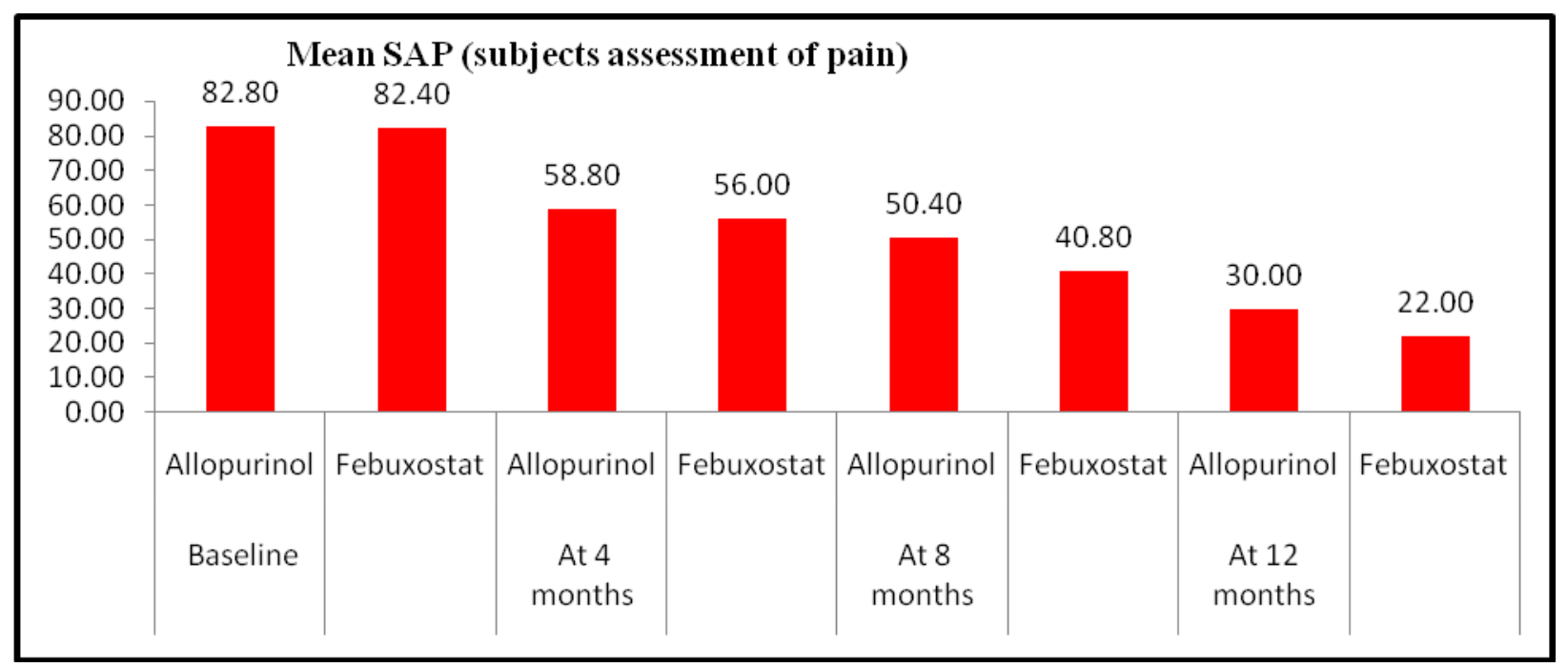


Table.4 SAD (subject's assessment of Disease activity) from baseline to 12 months

\begin{tabular}{|c|c|c|c|c|c|c|}
\hline $\begin{array}{c}\text { SAD (subjects assessment of } \\
\text { disease activity) }\end{array}$ & Drug group & Mean & S.D. & $\begin{array}{c}\text { t-test } \\
\text { value }\end{array}$ & $\begin{array}{c}\text { Mean } \\
\text { Difference }\end{array}$ & P-value \\
\hline Baseline & Allopurinol & 84.00 & 5.00 & 1.608 & 2.400 & 0.114 \\
\hline & Febuxostat & 81.60 & 5.54 & & & \\
\hline At 4 months & Allopurinol & 60.80 & 10.38 & 2.575 & 6.800 & $0.013^{*}$ \\
\hline & Febuxostat & 54.00 & 8.17 & & & \\
\hline At 8 months & Allopurinol & 46.80 & 8.02 & 3.176 & 8.000 & $0.003^{*}$ \\
\hline At 12 months & Febuxostat & 38.80 & 9.71 & & & \\
\hline & Allopurinol & 35.20 & 10.85 & 2.736 & 8.000 & $0.009^{*}$ \\
\hline & Febuxostat & 27.20 & 9.80 & & & \\
\hline
\end{tabular}

\section{Mean SAD (subjects assessment of disease activity)}

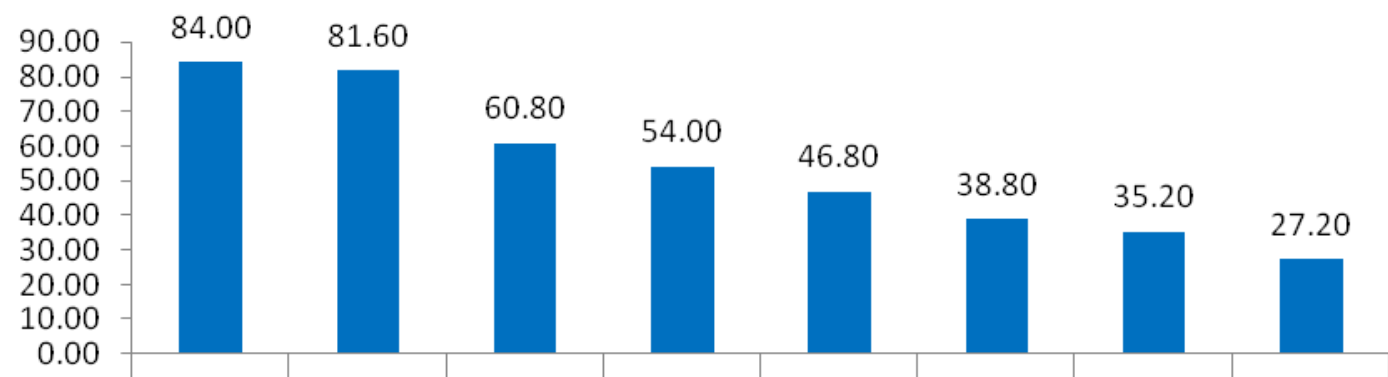

AllopurinolFebuxostatAllopurinol FebuxostatAllopurinolFebuxostatAllopurinolFebuxostat

\begin{tabular}{|l|l|l|l} 
Baseline & $\begin{array}{c}\text { At 4 } \\
\text { months }\end{array}$ & $\begin{array}{c}\text { At 8 } \\
\text { months }\end{array}$ & $\begin{array}{c}\text { At 12 } \\
\text { months }\end{array}$
\end{tabular}

Table.5 PAD (Physicians assessment of Disease activity) from baseline to 12 months

\begin{tabular}{|c|c|c|c|c|c|c|}
\hline $\begin{array}{c}\text { PAD (physicians assessment } \\
\text { of disease activity) }\end{array}$ & Drug group & Mean & S.D. & $\begin{array}{c}\text { t-test } \\
\text { value }\end{array}$ & $\begin{array}{c}\text { Mean } \\
\text { Difference }\end{array}$ & P-value \\
\hline Baseline & Allopurinol & 82.00 & 7.64 & -0.894 & -2.000 & 0.376 \\
\hline & Febuxostat & 84.00 & 8.17 & & & \\
\hline At 4 months & Allopurinol & 56.80 & 14.35 & 1.130 & 3.600 & 0.264 \\
\hline & Febuxostat & 53.20 & 6.90 & & & \\
\hline At 8 months & Allopurinol & 42.40 & 8.31 & 3.286 & 7.200 & $0.002^{*}$ \\
\hline & Febuxostat & 35.20 & 7.14 & & & \\
\hline At 12 months & Allopurinol & 35.20 & 12.95 & 2.545 & 8.000 & $0.014^{*}$ \\
\hline & Febuxostat & 27.20 & 8.91 & & & \\
\hline
\end{tabular}




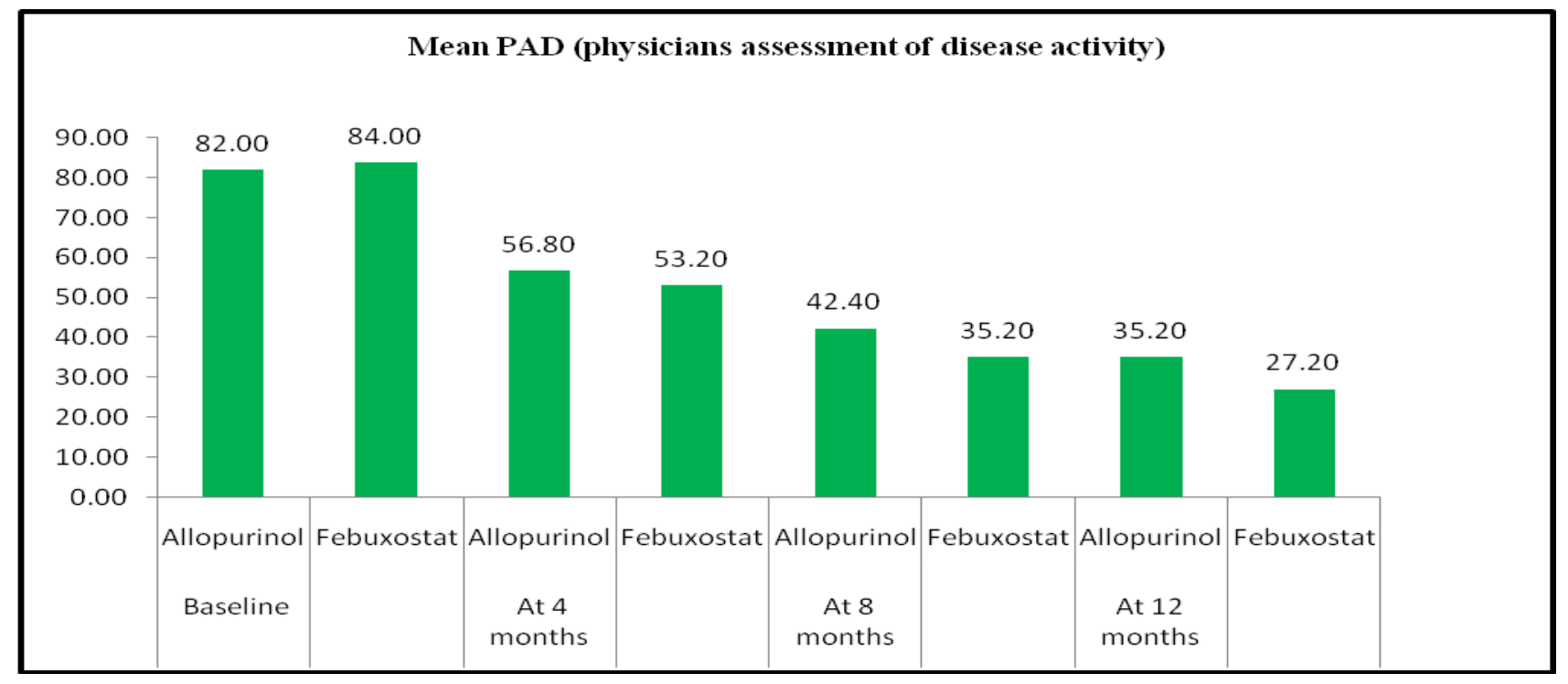

Table.6 Serum Uric Acid Level from baseline to 12 months

\begin{tabular}{|l|l|l|l|l|l|l|}
\hline Serum uric acid level & Drug group & Mean & S.D. & $\begin{array}{l}\text { t-test } \\
\text { value }\end{array}$ & $\begin{array}{l}\text { Mean } \\
\text { Difference }\end{array}$ & P-value \\
\hline Baseline & Allopurinol & 9.13 & 0.45 & -0.697 & -0.109 & 0.489 \\
\hline & Febuxostat & 9.24 & 0.64 & & & \\
\hline At 4 months & Allopurinol & 8.01 & 0.89 & 1.207 & 0.261 & 0.233 \\
\hline & Febuxostat & 7.75 & 0.62 & & & \\
\hline At 8 months & Allopurinol & 6.66 & 1.27 & 2.402 & 0.681 & $0.020^{*}$ \\
\hline & Febuxostat & 5.98 & 0.63 & & & \\
\hline At 12 months & Allopurinol & 6.32 & 1.42 & 2.871 & 0.882 & $0.006^{*}$ \\
\hline & Febuxostat & 5.44 & 0.59 & & & \\
\hline
\end{tabular}

Mean SERUM URIC ACID LEVEL

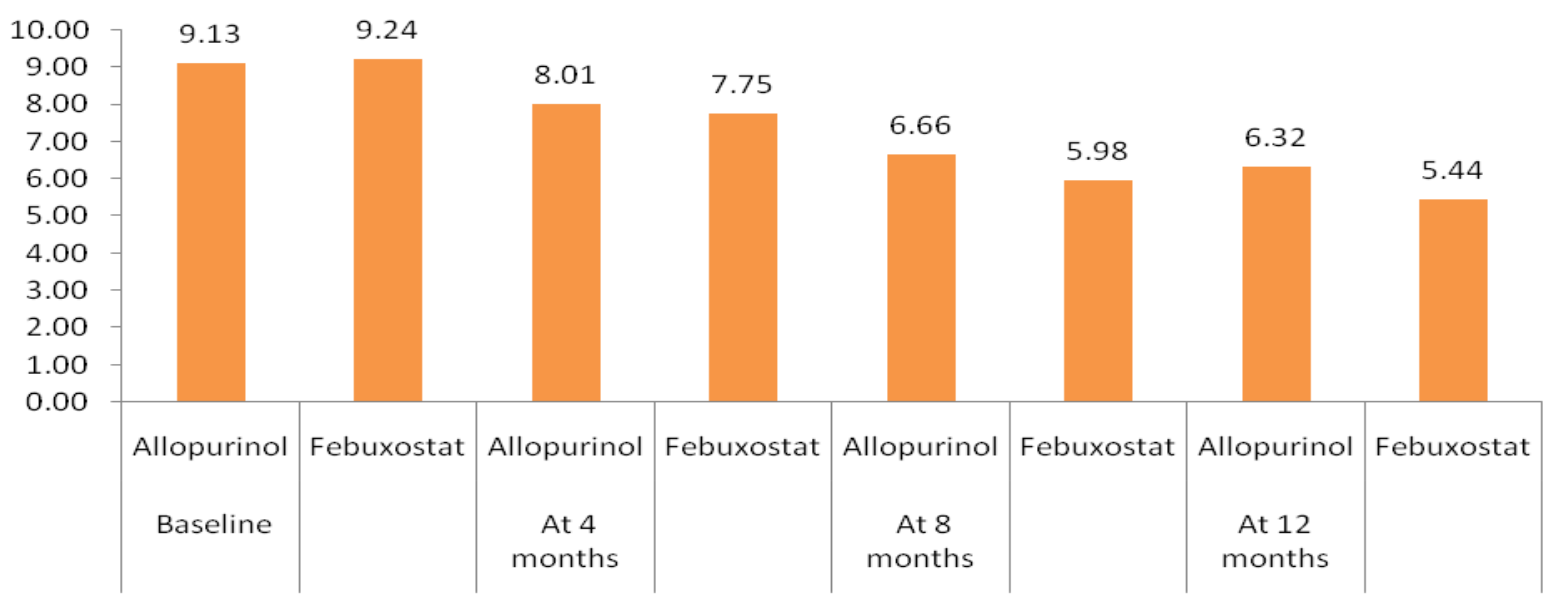


Table.7 Number of TOPHI from baseline to 12 month

\begin{tabular}{|l|l|l|l|l|l|l|}
\hline NO. OF TOPHI & Drug group & Mean & S.D. & $\begin{array}{l}\text { t-test } \\
\text { value }\end{array}$ & $\begin{array}{l}\text { Mean } \\
\text { Difference }\end{array}$ & P-value \\
\hline Baseline & Allopurinol & 4.20 & 0.76 & -1.095 & -0.200 & 0.279 \\
\hline & Febuxostat & 4.40 & 0.50 & & & \\
\hline At 4 months & Allopurinol & 4.20 & 0.76 & 3.286 & 0.600 & $0.002^{*}$ \\
\hline & Febuxostat & 3.60 & 0.50 & & & \\
\hline At 8 months & Allopurinol & 2.36 & 0.95 & 1.917 & 0.440 & 0.061 \\
\hline & Febuxostat & 1.92 & 0.64 & & & \\
\hline At 12 months & Allopurinol & 2.04 & 0.79 & 2.979 & 0.560 & $0.005^{*}$ \\
\hline & Febuxostat & 1.48 & 0.51 & & & \\
\hline
\end{tabular}

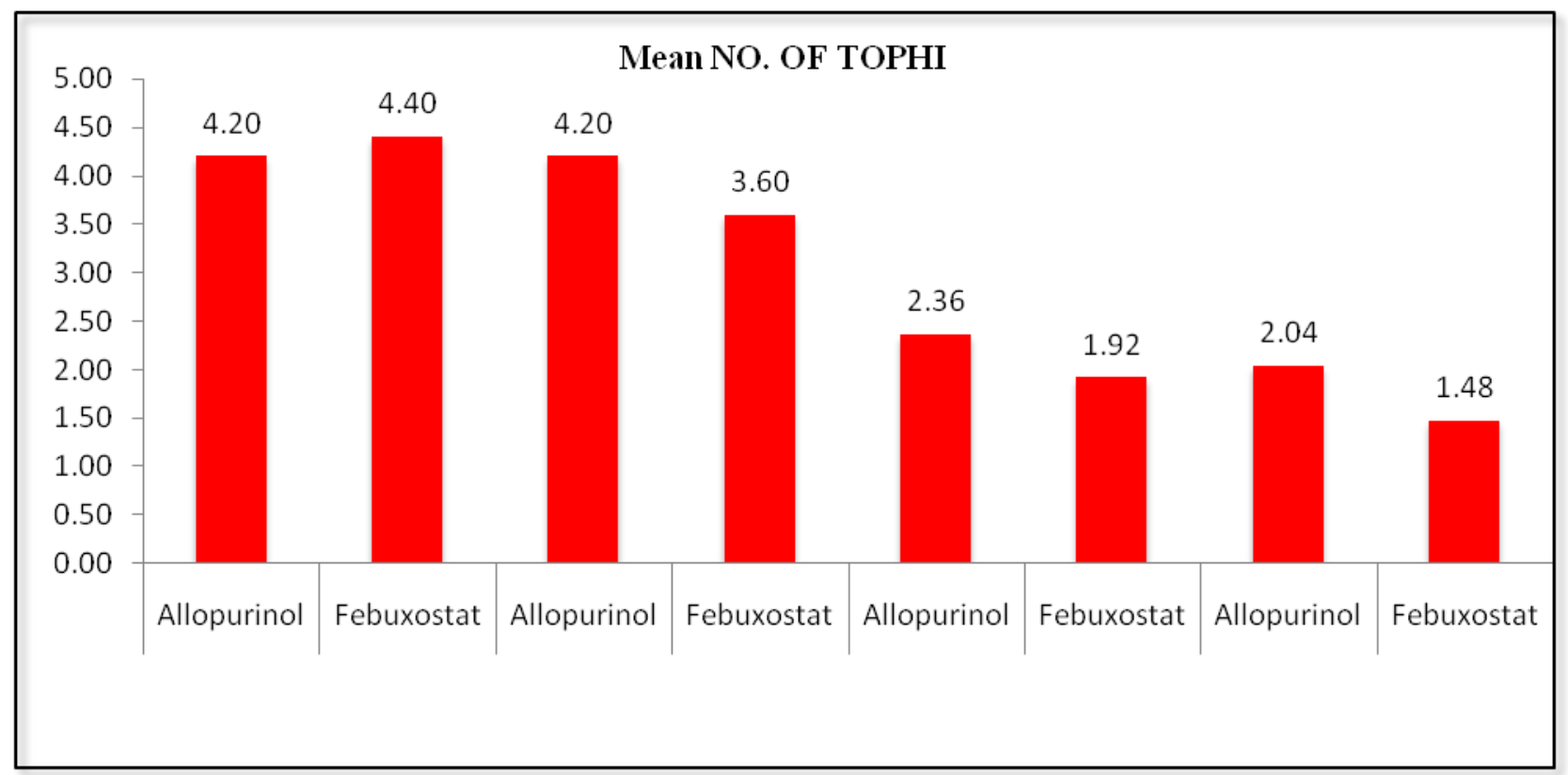

Table.8 Gout Flares from baseline to 12 months

\begin{tabular}{|l|l|l|l|l|l|l|}
\hline Gout flares & Drug group & Mean & S.D. & $\begin{array}{l}\text { t-test } \\
\text { value }\end{array}$ & $\begin{array}{l}\text { Mean } \\
\text { Difference }\end{array}$ & P-value \\
\hline Baseline & Allopurinol & 4.60 & 0.50 & -1.549 & -0.200 & 0.128 \\
\hline & Febuxostat & 4.80 & 0.41 & & & \\
\hline At 4 months & Allopurinol & 4.20 & 0.41 & -1.549 & -0.200 & 0.128 \\
\hline & Febuxostat & 4.40 & 0.50 & & & \\
\hline At 8 months & Allopurinol & 2.08 & 0.57 & 1.207 & 0.200 & 0.233 \\
\hline & Febuxostat & 1.88 & 0.60 & & & \\
\hline At 12 months & Allopurinol & 1.72 & 0.46 & 2.292 & 0.360 & $0.026^{*}$ \\
\hline & Febuxostat & 1.36 & 0.64 & & & \\
\hline
\end{tabular}




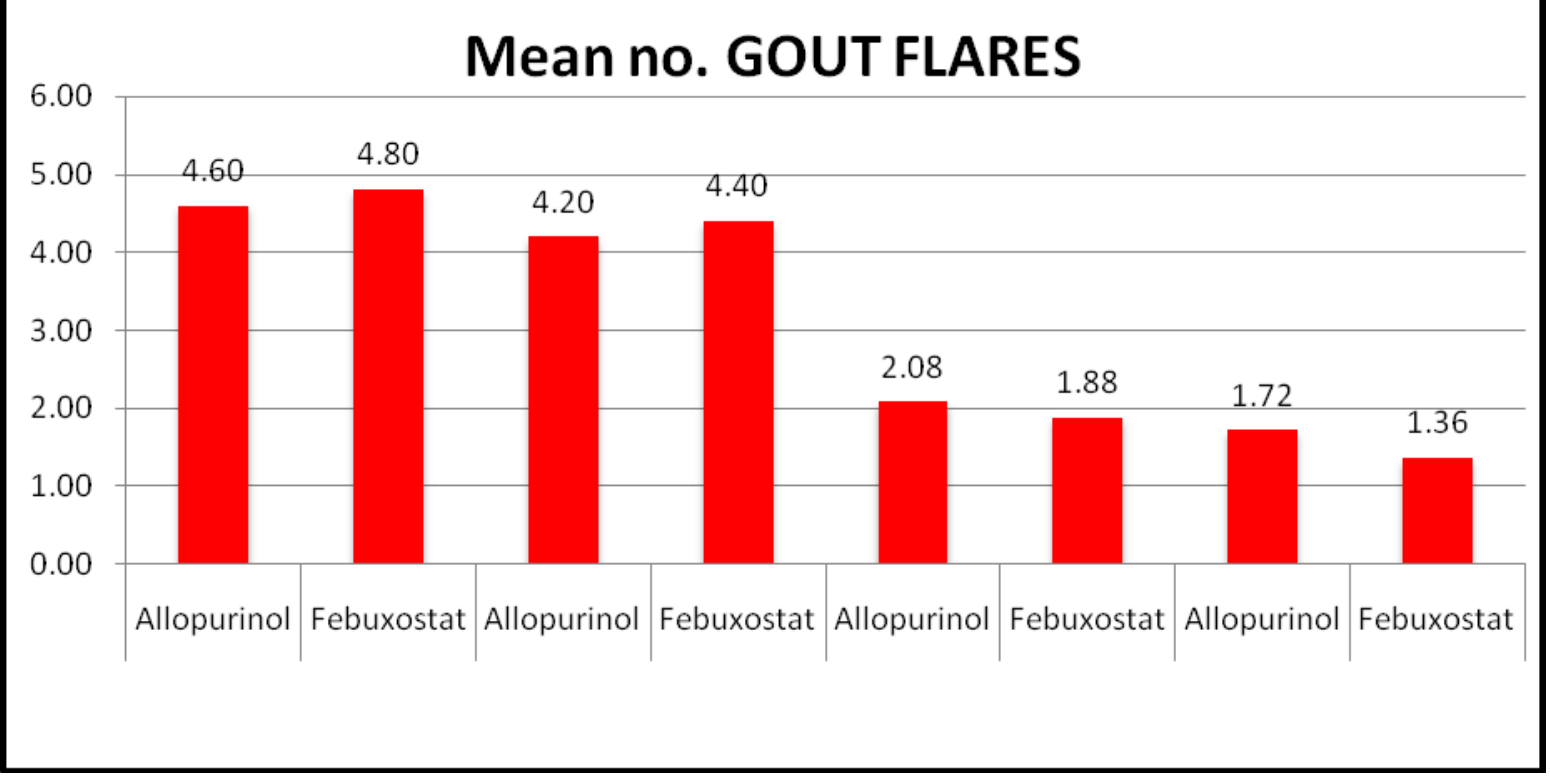

Fig.1 Steps catalysed by xanthine oxidase (XO) in the breakdown of purines into uric acid. The figure shows the steps that are inhibited by oxypurinol. (Adapted from Pacher et al., 2006).

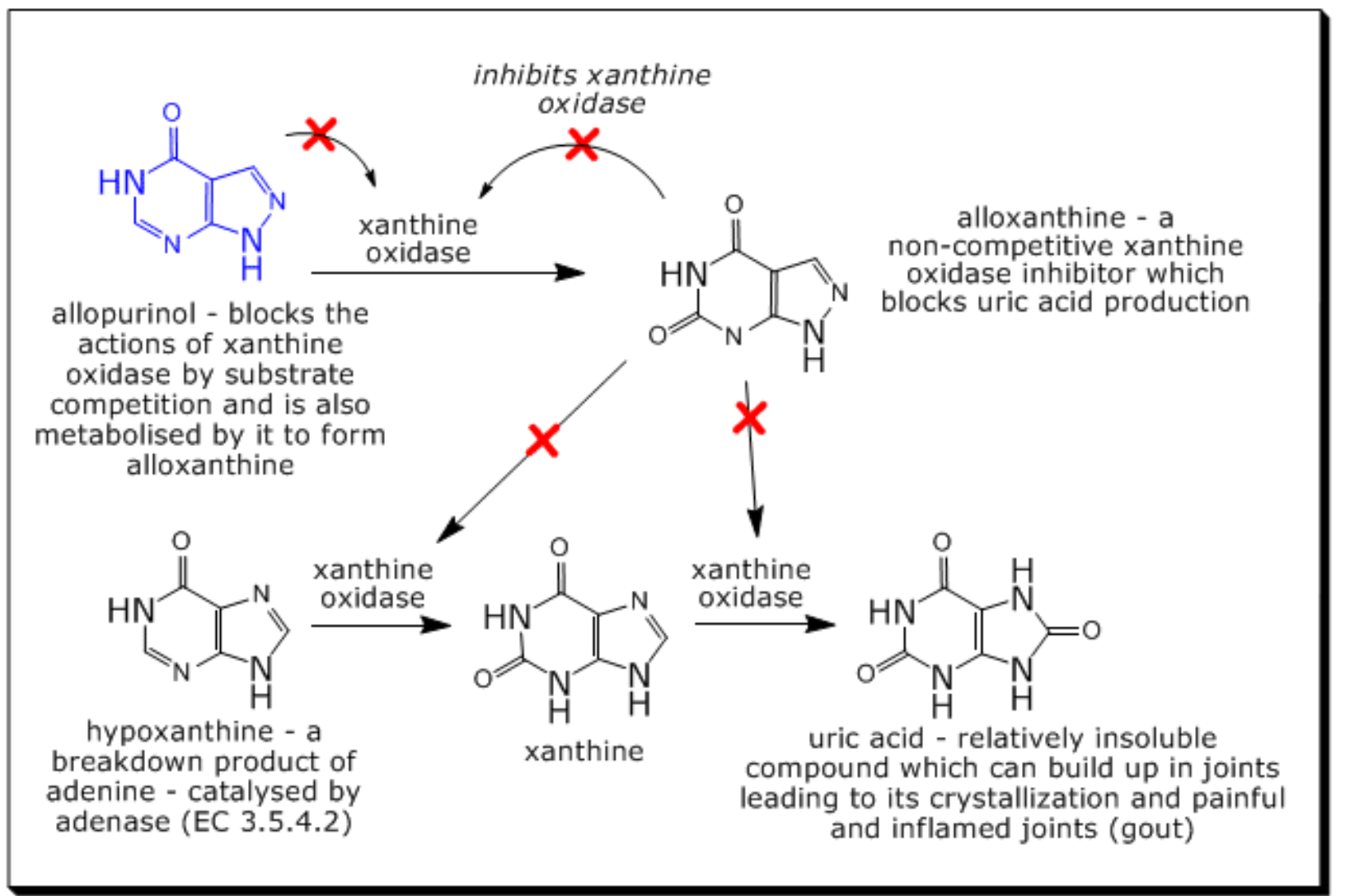

The secondary efficacy end point was the percentage reduction from baseline sUA at each study visit and maintained sUA $<6.0$ mg/dl. Among all subjects, mean \% sUA reductions from baseline ranged from 7 to $18 \%$ and 9 to $26 \%$ across all visits for 
allopurinol and febuxostat respectively. Allopurinol and febuxostat both decreased the serum uric acid level but febuxostat was more effective than allopurinol. At each visit, the sUA decreased but statistically significant difference was seen at $8^{\text {th }}$ month and at $12^{\text {th }}$ month and maintained their sUA level $<6.0 \mathrm{mg} / \mathrm{dl}$. Schumacher et al., showed that mean \% sUA reductions from baseline ranged from 45 to $59 \%$ across all visits. Across doses \% reductions in sUA were similar at final visit, with $\%$ reductions from baseline of 49.2, 47.1, and 50.7\% for febuxostat doses of 40,80 and $120 \mathrm{mg}$ respectively. Maintenance of sUA in this range has resulted in clinical benefits of tophus resolution and decreased gout flare incidence over the long term. Another study also showed that febuxostat, at a daily dose of $80 \mathrm{mg}$ or $120 \mathrm{mg}$, was more effective than allopurinol at the commonly used fixed daily dose of $300 \mathrm{mg}$ in lowering serum urate (Becker et al., 2005).

Becker et al., showed that febuxostat was more effective than allopurinol in terms of reductions of gout flares and no. of tophi. Present study also showed that febuxostat was more effective in reducing the no. of tophi. At the end of the $4^{\text {th }}$ month and $12^{\text {th }}$ month statistically significant difference was seen, at the end of the $8^{\text {th }}$ month no. of tophi decreases but no statistical difference was observed. Gout flares diminished at the end of the $12^{\text {th }}$ month. Schumacher et al., showed that the percentage of subjects that required treatment for gout flares declined to zero during the $5^{\text {th }}$ year of treatment.

Jackson et al., showed that febuxostat 80mg was significantly more efficacious than febuxostat $40 \mathrm{mg}$ or allopurinol in achieving the sUA $<6.0 \mathrm{mg} / \mathrm{dl}$ in gout patient's $\geq 65$ years of age. Febuxostat $40 \mathrm{mg}$ was also superior to allopurinol in this population. In subjects with mild to moderate renal impairment, significantly greater ULT efficacy was observed with febuxostat 40mg and $80 \mathrm{mg}$. Flare rates declined steadily in all treatment groups. Becker et al., also proved that urate lowering efficacy of febuxostat 80 mg exceeded that of febuxostat $40 \mathrm{mg}$ and allopurinol (300/200mg). In subjects with mild/moderate renal impairment, both febuxostat doses were more efficacious than allopurinol and equally safe.

Both the urate lowering drugs (Allopurinol and Febuxostat) reduces the sUA level and provides the symptomatic pain relief in the patients with hyperuricemia and gout. Both drugs improve the functionality of the joints and improve the quality of life of the patients with gout. Long term maintenance of both the drugs provides the reduction in the gout flare and no. of tophi. Both drugs are well tolerated and quite safe.

In conclusion, from this study it was concluded that Visual analogue scales proved to be a valid measure of gout activity. It was found that patients tend to slightly overestimate their level of disease activity when comparing patient responses to those of physician. VAS pain, SF-36 pain and patient global VAS are valid outcome measures in patients with chronic gout. Febuxostat and allopurinol provided symptomatic and functional relief in the patients with gout. However, in the view of statistical data, we consider that febuxostat is the first choice if early considerable symptomatic improvement is required. Both allopurinol and febuxostat are effective in the treatment of chronic hyperuricemia. Febuxostat has some advantages over allopurinol, being a non-purine xanthine oxidase inhibitor with lesser side effects and drug interaction. Long term use of these drugs reduces the gout flare, tophi and maintains the sUA $<6.0 \mathrm{mg} / \mathrm{dl}$. 


\section{References}

Agabiti-Rosei, E., Grassi, G. 2013. Beyond gout: uric acid and cardiovascular diseases. Curr. Med. Res. Opin., 29 suppl 3: 33-39.

Becker, M.A., Schumacher, H.R., Espinoza, L.R., Wells, A.F. et al. 2010. The urate lowering efficacy and safety of febuxostat in the treatment of the hyperuricemia of gout: This confirms trial. Arth. Res. Ther., 12: r63.

Becker, M.A., Schumacher, H.R. et al. 2005. Febuxostat compared with allopurinol in patients with hyperuricemia and gout. $N$ Engl. J. Med., 353(23): 2450-61.

Borghi, C., Rosei, E.A., Bardin, T., Dawson, J., Dominiczak, A., Kielstein, J.T., Manolis, A.J., Perez-Ruiz, F., Mancia, G. 2015. Serum uric acid and the risk of cardiovascular and renal disease. $J$. Hypertens, 33: 1729- 1741.

Choi, H.K., Atkinson, K., Karlson, E.W., Curhan, G. 2005. Obesity, weight change, hypertension, diuretic use, and risk of gout in men: the health professionals' follow-up study. Arch. Intern. Med., 165: 742-748.

Choi, H.K., Atkinson, K., Karlson, E.W., Willett, W., Curhan, G. 2004. Purinerich foods, dairy and protein intake, and the risk of gout in men. $N$ Engl. J. Med., 350(11): 1093-103.

Choi, J.W., Ford, E.S., Gao, X., Choi, H.K. 2008. Sugar-sweetened soft drinks, diet soft drinks, and serum uric acid level: The third national health and nutrition examination survey. Arthritis Rheum., 59: 109-116.

Desideri, G., Castaldo, G., Lombardi, A., Mussap, M., Testa, A., Pontremoli, R., Punzi, L., Borghi, C. 2014. Is it time to revise the normal range of serum uric acid levels? Eur. Rev. Med. Pharmacol. Sci., 18: 1295- 3067.
Dincer, H.E., Dincer, A.P., Levinson, D.J. 2002. Asymptomatic hyperuricemia: to treat or not to treat. Cleve Clin. J. Med., 69(8): 594.

Doherty, M., Jansen, T.L., Nuki, G., Pascual, E., Perezruiz, F., Punzi, L., So, A.K., Bardin, T. 2012. Gout: why is this curable disease so seldom cured? Ann. Rheum. Dis., 71: 17651770.

Falasca, G.F. 2006. Metabolic diseases: Gout. Clin. Dermatol., 24: 498-508.

Jackson, R.L., Hunt, B. and Macdonald, P.A. 2012. The efficacy and safety of febuxostat for urate lowering in gout patient's $\geq 65$ years of age. $B M C$ Geriatrics, 12: 11.

Khanna, D., Fitzgerald, J.D., Khanna, P.P. et al. 2012. American College of Rheumatology guidelines for management of gout. Part 1: systematic nonpharmacologic and pharmacologic therapeutic approaches to hyperuricemia. Arthritis Careres (hoboken), 64: 1431-46.

Kim, K.Y., Schumacher, H.R., Hunsche, E., Wertheimer, A.L., Kong, S.X. 2003. A literature review of epidemiology and treatment of acute gout. Clin. Ther., 25(6): 1593-617.

Matthew, A., Danda, D. 2004. Clinical profile of young onset gout in India. $J$. Ind. Rheum. Assoc., 12-8.

Misra, A., Khurana, I. 2008. Obesity and the metabolic syndrome in developing countries. J. Clin. Endocrinol. Metab., 93: s9-30.

Nuki, G. 2008. Colchicine: its mechanism of action and efficacy in crystal-induced inflammation. Curr. Rheumatol. Rep., 10: 218-27.

Nuki, G., Simkin, P.A. 2006. A concise history of gout and hyperuricemia and their treatment. Arthritis Res Ther. 2006; 8 suppl 1: s1. Epub. 
Richette, P., Clerson, P., Périssin, I., Flipo, R.M., Bardin, T. 2015. Revisiting comorbidities in gout: A cluster analysis. Ann. Rheum. Dis., 74: 142147.

Ruilope, L.M., Pontremoli, R. 2013. Serum uric acid and cardio-renal diseases. Curr. Med. Res. Opin., 29 suppl 3: 2531.

Schumacher, H.R., Becker, M.A., Ltoyd, E., Macdonald, P.A., Lademacher, C. 2009. Febuxostat in the treatment of gout: 5-yr findings of the focus efficacy and safety study. Rheumatol., (oxford), 48: 188-94.

Singh, J.A., Yang, S., Strand, V,. Simon, L,. Forsythe, A., Hamburger, S. et al. 2001. Validation of pain and patient global scales in chronic gout: data from two randomised controlled trials. Ann. Rheum. Dis., 70: 1277-1281.

Smith, E., Hoy, D., Cross, M., Merriman, T.R., Vos, T., Buchbinder, R., Woolf, A. 2014. The global burden of gout: estimates from the global burden of disease 2010 study. Ann. Rheum. Dis., 73: 1470-1476.
Taylor, T.H., Mecchella, J.N., Larson, R.J., Kerin, K.D., Mackenzie, T.A. 2012. Initiation of allopurinol at first medical contact for acute attacks of gout: a randomized clinical trial. American J. Med., 125: 1126-1134.

Wallace, S.L., Robinson, H., Masi, A.T., Decker, D.J., Mccarty, D.J., Yü, T.F. 1977. Preliminary criteria for the classification of the acute arthritis of primary gout. Arthritis Rheum., 20: 895-900.

Zhang, W., Doherty, M., Pascual, E., Bardin, T., Barskova, V., Conaghan, P., Gerster, J., Jacobs, J., Leeb, B., Lioté, F., Mccarthy, G., Netter, P., Nuki, G., Perez-Ruiz, F., Pignone, A., Pimentão, J., Punzi, L., Roddy, E., Uhlig, T., Zimmermann-Gòrska, I. 2006. Eular standing committee for international clinical studies including therapeutics. Eular evidence based recommendation for gout. Part two. Management: results of a task force of the standing commettee for international studies including therapeutics. Ann. Rheum. Dis., 65: 1312-1328.

\section{How to cite this article:}

Shikhar Tyagi, Shalini Rawat, Sarika Saxena. 2016. Comparative Study between Febuxostat and Allupurinol based on Safety and Urate-Lowering Efficacy in Gout Patients of Indian Population. Int.J.Curr.Microbiol.App.Sci. 5(9): 801-815. doi: http://dx.doi.org/10.20546/ijcmas.2016.509.091 